\title{
Geotecnologia aplicada ao desflorestamento aponta $92 \%$ de desflorestamento ilegal em projeto de assentamento cedro no município de Tartarugalzinho no estado do Amapá
}

No Estado do Amapá a agricultura familiar nos projetos de assentamentos é responsável por grande parte do desflorestamento, esta atividade é desenvolvida através de roças, que possui um sistema de revezamento de terras, caracterizando o chamado desmatamento silencioso, que são difíceis de serem detectados por imagens de satélites, variando em uma área de no máximo 3 hectares. Sem a distinção do desmatamento legal do ilegal, não é possível direcionar ações e políticas públicas aplicadas diretamente às atividades ilegais. O objetivo principal desta pesquisa foi analisar o impacto do desflorestamento ilegal no desflorestamento total do Projeto de Assentamento - PA Cedro no município de Tartarugalzinho no Estado do Amapá, através de ferramentas de geotecnologia no período de 2009 a 2014. Para a análise espacial foi utilizado o Sistema de Informação Geográfica (SIG), o software utilizado foi o ArcGIS, através de comparação das áreas desmatadas e espacialização das autorizações de desmatamento emitidas para cada lote do assentamento. Os resultados mostraram que no período de 2009 a 2014 o desmatamento ilegal chegou a 92,89\%, sendo que o biênio 2011/2012 demonstrou uma taxa de desmatamento não autorizado de $97,76 \%$. Ficou evidente que a geotecnologia é uma ferramenta muito útil devido à sua funcionalidade, demonstrando a possibilidade e necessidade da aplicação de geoprocessamento para a análise do desmatamento legal, com a espacialização das autorizações de desmatamento no projeto de assentamento.

Palavras-chave: Agricultura Familiar; Projeto de Assentamento; Geotecnologia.

\section{Geotechnology applied against deforestation point to $92 \%$ illegal deforestation in cedro settlement project (sp) in the municipality of Tartarugalzinho in Amapá State}

In Amapá State, family agriculture in settlement projects accounts for a large part of deforestation. This activity is developed through small crops, which has a relay cropping system, characterizing the so-called silent deforestation, which are difficult to detect by satellite images, varying to a maximum area of 3 hectares. Without the distinction of legal deforestation from illegal, it is not possible to guide public actions and policies directly applied to illegal activities. The main goal of this research was to analyze the impact of illegal deforestation on the total deforestation of the Cedro Settlement Project (SP) in the municipality of Tartarugalzinho in Amapá State, using geotechnology tools from 2009 to 2014. For spatial analysis, the Geographic Information System (GIS), the software used was ArcGIS, by correlate deforested areas and environmental authorizations issued for each settlement lot. The results showed that from 2009 to 2014 , illegal deforestation reached $92.89 \%$, and the biennium 2011/2012 demonstrated an unauthorized deforestation rate of $97.76 \%$. It was evident that geotechnology is a prominent tool due to its functionality, demonstrating the possibility and necessity of applying geoprocessing to the analysis of legal deforestation, with the spatialization of deforestation authorizations in the settlement project.

Keywords: Family Agriculture; Settlement Project; Geotechnology.

Topic: Tecnologia, Modelagem e Geoprocessamento

Reviewed anonymously in the process of blind peer.

José Douglas Monteiro da Costa (iD)

Universidade Federal do Amapá, Brasil

http://lattes.cnpq.br/7756200053701768

http://orcid.org/0000-0002-1710-7686

cientistaambiental2012@gmail.com
Received: 10/06/2018

Approved: 24/07/2018
Referencing this:

COSTA, J. D. M.. Geotecnologia aplicada ao desflorestamento aponta 92\% de desflorestamento ilegal em projeto de assentamento cedro no município de Tartarugalzinho no estado do Amapá. Revista Ibero Americana de Ciências Ambientais, v.9, n.5, p.330-340, 2018. DOI: http://doi.org/10.6008/CBPC2179-6858.2018.005.0029 
Geotecnologia aplicada ao desflorestamento aponta 92\% de desflorestamento ilegal em projeto de assentamento cedro no município de

\section{INTRODUÇÃO}

O desflorestamento legal, diferente das atividades ilegais contra a biodiversidade, tem o objetivo em conciliar os aspectos ambientais com o econômico em uma sociedade. Todavia, deve ser uma atividade planejada, monitorada e fiscalizada pelo Estado, para não comprometer o meio ambiente e o interesse público. Conforme Grisi (2000) e Milaré (2009) o desflorestamento é um processo, de origem antrópica, e tem o objetivo de supressão da cobertura vegetal nativa de uma mata ou floresta, para a finalidade de expansão urbana, agricultura e utilização de madeira, dentre outros.

A floresta urbanizada, de acordo com Becker $(1995,2001)$, e a condição de vida nos assentamentos e cidades contribuem para os maiores problemas ambientais. A vegetação nativa na Amazônia vem sofrendo modificações durante as últimas décadas (BECKER, 2005). A agricultura (FEARNSIDE, 1999), pecuária (MARGULIS, 2003; WALKER et al., 2000), e a exploração de madeira (FEARNSIDE, 2003) são as maiores responsáveis pelo desflorestamento. Os assentamentos são os principais causadores de desflorestamento na Amazônia nos últimos anos. O desflorestamento tem sido destacado principalmente pela mudança no tamanho dos polígonos, passando de grande para pequenas áreas (ALENCAR et al., 2013).

A agricultura é uma das atividades de maior causa do desflorestamento (KITAMURA, 1994), que chega aproximadamente a 50\% do total de desmatamento (HOMMA et al., 1995). Fearnside (2001) destaca que a agricultura em assentamentos rurais faz parte das atividades que mais causam impactos a vegetação nativa. Para Batista (2009), os desflorestamentos realizados nos projetos de colonização e assentamentos, somam $25,5 \%$ do total de áreas desmatadas no Estado do Amapá.

O desflorestamento realizado sem autorização emitida pelos órgãos ambientais competentes é denominado de ilegal ou não autorizado, e traz consequências negativas ao meio ambiente. No Estado do Amapá a agricultura familiar é responsável por grande parte do desflorestamento, esta atividade é desenvolvida através de roças, que possui um sistema de revezamento de terras, variando em uma área de no máximo 3 hectares (DOMINGUES et al., 2004; AMAPÁ, 2009). Este revezamento correlacionado com a variação da área produz constante desmate e queimada, caracterizando o chamado desmatamento silencioso, que são difíceis de serem detectados por imagens de satélites (DOMINGUES et al., 2004).

A maior pressão de desflorestamento se concentra em torno dos eixos das rodovias BR-156 e BR210, no sentido dos municípios de Macapá-Oiapoque. A expansão da pecuária e da agricultura ocasionam queimadas, junto com o avanço desenfreado da exploração madeireira ilegal e os projetos de assentamentos (AMAPÁ, 2014; LEMOS et al., 2011).

As atividades causadoras do desflorestamento têm levado às consequências severas contra o meio ambiente, ao setor econômico e a sociedade (BRASIL, 2003; MMA, 2004). Para Kitamura (1994) o desflorestamento, além de apresentar consequências no âmbito local e regional, afeta também o planeta, resultando em mudanças climáticas causadas pela perda do revestimento florestal, o efeito estufa causado pela queima de madeira, aumento da sedimentação dos rios, erosão, degradação do solo e perda da biodiversidade. 
Geotecnologia aplicada ao desflorestamento aponta 92\% de desflorestamento ilegal em projeto de assentamento cedro no município de

Um dos maiores desafios atuais consiste em diferenciar o desflorestamento ilegal do legal, para que se possa efetivamente extinguir o ilegal e promover políticas públicas para reduzir a supressão legal, sem prejuízo do desenvolvimento local. O desflorestamento legal, diferente das atividades ilegais contra a biodiversidade, tem o objetivo em conciliar os aspectos ambientais com o econômico de uma sociedade. Todavia, deve ser uma atividade planejada, monitorada e fiscalizada pelo Estado, para não comprometer o meio ambiente e o interesse público.

Com a Lei Federal № 11.284, de 2 de março de 2006, a gestão florestal passou a ser atribuição do Estado, executada pela Secretaria de Meio Ambiente do Estado do Amapá (SEMA) e pelo Instituto de Meio Ambiente e Ordenamento Territorial do Estado do Amapá (IMAP). As autorizações são emitidas pelo IMAP usando o Sistema de Produtos Florestais (SISPROF) do Instituto Brasileiro do Meio Ambiente e dos Recursos Naturais Renováveis (IBAMA), em conformidade com a Instrução Normativa № 3, de 4 de março de 2002 IBAMA e a Instrução Normativa № 75, de 25 de agosto de 2005-IBAMA, que tratam de autorizações de desmatamento.

O município de Tartarugalzinho no biênio de 2013/2014 foi o que mais desmatou no estado do Amapá, uma área de aproximadamente 16,18 km² (AMAPÁ, 2014). Para o biênio 2013-2014 o desmatamento em projetos de assentamentos foi da ordem de 21,27 km². A maior incidência de desmatamento ocorreu nos assentamentos localizados na região central e ao norte do estado. O Projeto de Assentamento - PA Cedro somou $2,07 \mathrm{~km}^{2}$, sendo um dos que mais desmataram no Estado.

Para monitorar o desmatamento ilegal do Estado é necessário que ocorra o monitoramento do desmatamento de todo território, pois apenas assim é possível distinguir áreas alteradas legalmente das áreas alteradas ilegalmente. Diversos institutos de pesquisa ou de governo, como SEMA e INPE, fazem o monitoramento do desmatamento utilizando diferentes insumos e metodologias.

Segundo Catelani et al. (2003), o desenvolvimento das geotecnologias permitiu que o monitoramento, a fiscalização e até a aplicação da legislação ambiental consigam ser mais eficientes e com custo menor, pois são utilizadas em vistorias técnicas em propriedades e em monitoramento com período de tempo menor. Para Florenzano (2008) a utilização de ferramentas de geotecnologias pode-se mostrar os ambientes e as suas descaracterizações que são causados por intervenção antrópica, como o desflorestamento.

Sem a diferenciação do desmatamento ilegal do legal, devido à falta de estudos técnico-científicos, não é possível direcionar ações e políticas públicas aplicadas diretamente às atividades ilegais. Diante desta problemática, e com a utilização de técnicas de geoprocessamento, buscou-se nesta pesquisa levantar informações quantitativas das autorizações de desmatamento emitidas pelo IMAP. Partiu-se da hipótese que desflorestamento ilegal apresenta uma parcela superior no desflorestamento total no Projeto de Assentamento - PA Cedro. 
Geotecnologia aplicada ao desflorestamento aponta 92\% de desflorestamento ilegal em projeto de assentamento cedro no município de

O objetivo principal deste trabalho foi analisar o impacto do desflorestamento ilegal no desflorestamento total do Projeto de Assentamento - PA Cedro no município de Tartarugalzinho no Estado do Amapá, através de ferramentas de geotecnologia no período de 2009 a 2014.

\section{MATERIAIS E MÉTODOS}

\section{Área de estudo}

A Figura 1 representa a área de estudo do presente trabalho, o Projeto de Assentamento do Cedro, situado no Município de Tartarugalzinho, criado em 1996, capacidade para 600 famílias, sendo que 598 estão efetivamente assentadas, possui área total de $642,30 \mathrm{Km}^{2}$, com $611,29 \mathrm{Km}^{2}$ de área de floresta, caracterizada pela alta densidade e diversidade de espécies com estrutura de alto porte (ICMBIO, 2014; INCRA, 2016).

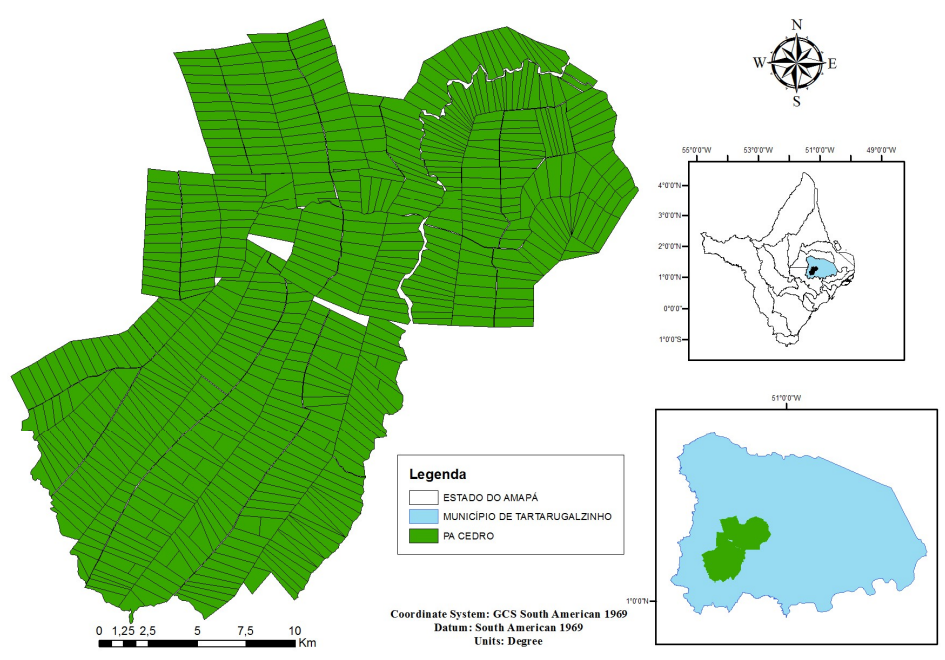

Figura 1: Localização do Projeto de Assentamento do Cedro.

\section{Obtenção dos dados}

Os dados sobre as autorizações de desmatamento foram obtidos no Núcleo de Documentação e Origem Florestal (NDOF), pertencente ao Instituto do Meio Ambiente e de Ordenamento Territorial (IMAP), em Macapá. Neste órgão, as autorizações de desmatamento são impressas e anexadas por ano. Cada autorização impressa foi consultada para extração das informações pertinentes ao estudo. A partir dessas informações um banco de dados foi elaborado em forma de planilha eletrônica.

Arquivos de extensão shapefile contendo os polígonos do desmatamento no Projeto de Assentamento Cedro foram obtidos junto à SEMA, a qual gera dados bianuais do desmatamento para o Amapá. Assim, informações para os anos de 2013-2014 foram obtidas (AMAPÁ, 2016). Apesar da SEMA não gerar dados anuais sobre o desmatamento, seus dados foram utilizados por serem mais precisos, devido ao método empregado, que consiste na utilização de imagens de satélite em melhor resolução espacial e na identificação de áreas a partir de 0,1 ha.

Para possibilitar a observação da relação entre autorização e desmatamento foi criado um projeto SIG, contendo as seguintes informações em formato shapefile: limite municipal, desmatamento (SEMA), 
Geotecnologia aplicada ao desflorestamento aponta 92\% de desflorestamento ilegal em projeto de assentamento cedro no município de

autorização do desmatamento, malha viária, áreas protegidas, projeto de assentamento e seus respectivos loteamentos.

\section{Espacialização das autorizações do desflorestamento}

Os dados de autorização, contidos na planilha, foram espacializados no programa ArcGIS, a partir das informações de suas coordenadas geográficas. Dessa forma, para cada autorização houve um ponto georreferenciado com suas respectivas atribuições: validade, ano, área autorizada, detentor, município e coordenadas.

Para identificação da área desmatada relacionada com cada autorização, foi feito um estudo detalhado para associar o desmatamento às autorizações, identificando qual área desmatada poderia estar associada a uma autorização. No caso dos assentamentos foi possível identificar o lote para o qual a autorização foi emitida. Identificado o lote, buscou-se dados sobre desmatamento em seu interior, o polígono foi associado à autorização do ano correspondente. Nos casos que não houve desmatamento em área autorizada, esta informação foi inserida na tabela de atributo do shapefile autorização.

\section{Análise dos dados}

A análise dos dados foi realizada através da comparação entre as áreas desmatadas e a espacialização dos polígonos de desmatamento relacionados às autorizações. Tabelas contendo a área total foram elaboradas para cada biênio da área autorizada para desmatamento, área do desmatamento legal e área do desmatamento ilegal. A partir das tabelas e gráfico foram gerados os percentuais do desmatamento legal e ilegal para cada biênio. Mapas foram elaborados, contendo os desmatamentos legais e ilegais para o período estudado. A visualização desta questão permitiu diversas análises sobre a possível relação com variáveis geográficas, tais como a proximidade de estradas com os lotes do assentamento.

\section{RESULTADOS}

A Tabela 1 e o Gráfico 1 mostram as informações gerais das áreas autorizadas e o desmatamento detectado. Evidencia-se que a maior área autorizada no PA Cedro foi no biênio de 2009/2010, com uma área de 108 hectares, sendo que foram detectados pela SEMA/AP, 426,21 hectares, representando um percentual de $25,34 \%$ autorizado e $74,66 \%$ não autorizado. O biênio 2011/2012 foi o que demonstrou a maior taxa de desmatamento não autorizado com 97,76\%. No período de 2009 a 2014 o desmatamento não autorizado chegou a $92,89 \%$.

É válido ressaltar que o aumento considerado visto na Tabela 1 e Gráfico 1 no biênio 2011/2012 pode ter sido em função do uso de imagens RapidEye, haja vista que este sensor possui resolução espacial superior à resolução das imagens Landsat, utilizadas nos biênios de 2009/2010 e 2013/2014. Conforme pode ser observado na Tabela 2, no período analisado na pesquisa (2009 a 2014) foram autorizadas 54 autorizações de desmatamento, dos quais 51 estavam hábeis a serem espacialmente localizados com coordenadas 
Geotecnologia aplicada ao desflorestamento aponta 92\% de desflorestamento ilegal em projeto de assentamento cedro no município de tartarugalzinho no estado do Amapá

geográficas (correspondendo a 150 ha), estando as 3 com coordenadas geográficas incompletas ou ausentes (correspondendo a 3 ha), não constando portanto, na Figura 2.

Tabela 1: Percentual das autorizações de desmatamento em relação aos desmatamentos detectados pela SEMA/AP no período de 2009 a 2014.

\begin{tabular}{|l|l|l|l|l|}
\hline BIÊNIO & $\begin{array}{l}\text { Área Autorizada para } \\
\text { desmatamento } \\
\text { IMAP/AP (ha) }\end{array}$ & $\begin{array}{l}\text { Desmatamento } \\
\text { detectado } \\
\text { SEMA/AP (ha) }\end{array}$ & $\begin{array}{l}\text { Percentual das } \\
\text { Autorizações } \\
\text { Desmatamento (\%) }\end{array}$ & $\begin{array}{l}\text { Percentual do } \\
\text { Desmatamento } \\
\text { Autorizado (\%) }\end{array}$ \\
\hline $2009 / 2010$ & 108,00 & 426,21 & 25,34 & 74,66 \\
\hline $2011 / 2012$ & 36,00 & 1604,11 & 2,24 & 97,76 \\
\hline $2013 / 2014$ & 15,00 & 207,00 & 7,25 & 92,75 \\
\hline TOTAL & $\mathbf{1 5 9 , 0 0}$ & $\mathbf{2 2 3 7 , 3 2}$ & $\mathbf{7 , 1 1}$ & $\mathbf{9 2 , 8 9}$ \\
\hline
\end{tabular}

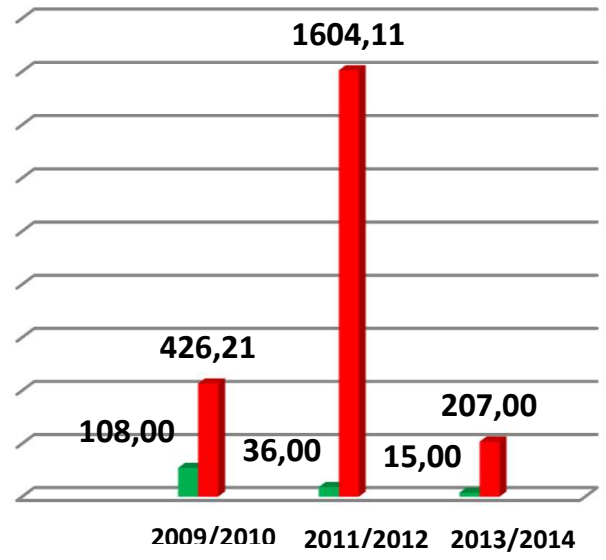

- Área Autorizada para desmatamento IMAP/AP (ha)

Desmatamento detectado SEMA/AP (ha)

Gráfico 1: Gráfico da área autorizada e desmatamento detectado.

Tabela 2: Quantidade e área de autorizações de desmatamento espacializadas e não espacializadas no período de 2009 a 2014.

\begin{tabular}{|l|l|l|l|l|l|}
\hline BIÊNIO & $\begin{array}{l}\text { Quantidade de } \\
\text { Autorizações } \\
\text { espacializadas }\end{array}$ & $\begin{array}{l}\text { Quantidade de } \\
\text { Autorizações não } \\
\text { espacializadas }\end{array}$ & $\begin{array}{l}\text { Área Autorizada } \\
\text { espacializada (ha) }\end{array}$ & $\begin{array}{l}\text { Área Autorizada } \\
\text { não espacializada } \\
\text { (ha) }\end{array}$ & $\begin{array}{l}\text { Área Total } \\
\text { Autorizada (ha) }\end{array}$ \\
\hline $2009 / 2010$ & 34 & 3 & 99,00 & 9,00 & 108,00 \\
\hline $2011 / 2012$ & 12 & 0 & 36,00 & 0,00 & 36,00 \\
\hline $2013 / 2014$ & 5 & 0 & 15,00 & 0,00 & 15,00 \\
\hline TOTAL & 51 & 3 & 150,00 & 9,00 & 159,00 \\
\hline Total & $\mathbf{5 4}$ & & & & \\
\hline
\end{tabular}

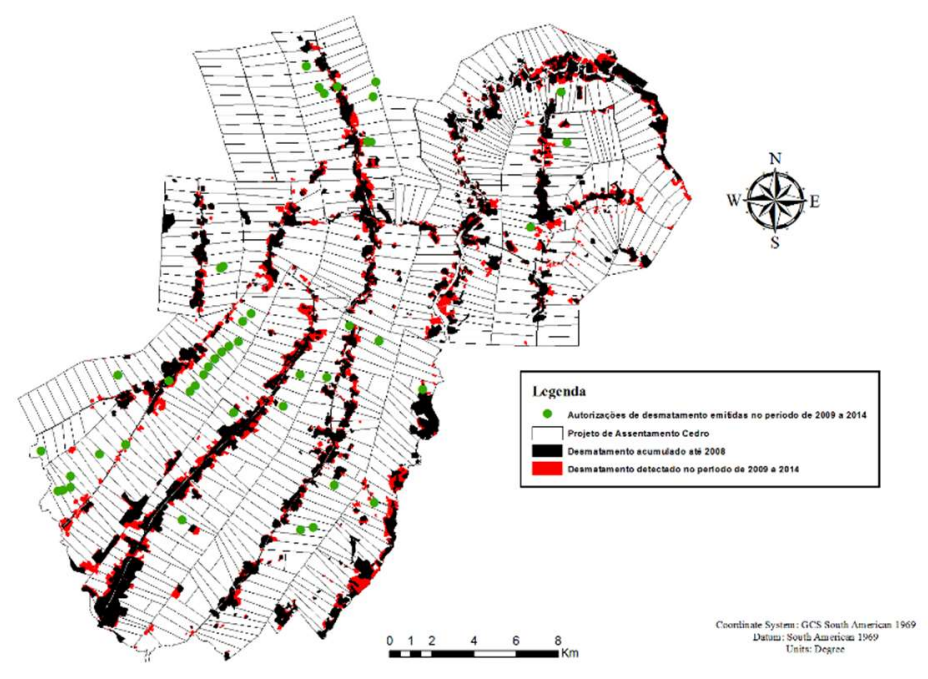

Figura 2: Plotagem das coordenadas geográficas das autorizações de desmatamento, no período de 2009 a 2014. 
A Figura 3 mostra a identificação dos polígonos de desmatamento para cada biênio em um lote X. No biênio de 2009/2010 não foi detectado desmatamento, porém, no biênio de 2011/2012 foram identificados 10,80 hectares de desmate ilegal, uma vez que, não foi emitida autorização para o lote neste período. A autorização para desmate com área de 3 hectares foi emitida no ano de 2014 com validade até 15/09/2015, sendo relacionada com o polígono de 1,41 hectare no ano de 2014. Não foi possível analisar o ano de 2015, pois o relatório técnico da SEMA/AP encontra-se em finalização. Mas, para o período de 2009 a 2014 pode-se afirmar que houve um desmatamento não autorizado de 10,80 hectares.

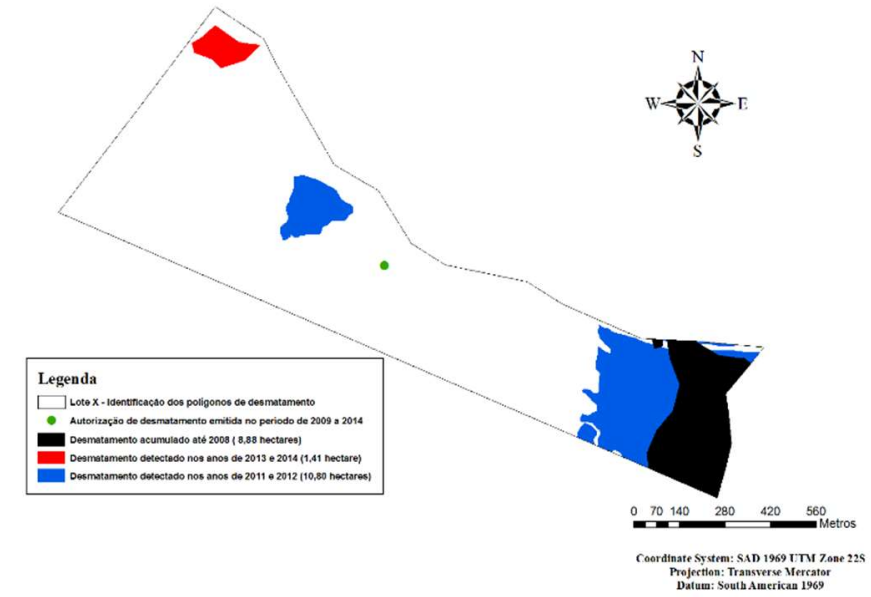

Figura 3: Mapa de identificação de desmatamento em um determinado lote.

\section{DISCUSSÃO}

Conforme os resultados obtidos na tabela 1 e gráfico 1, no biênio 2009/2010, o IMAP autorizou o desmate de 108,00 ha e foi detectada através de imagens de satélites pela SEMA, uma área de 426,21 ha de desflorestamento, ou seja, a área não autorizada correspondeu aproximadamente a $74,66 \%$ do desmatamento total no PA Cedro. No biênio 2011/2012, foi autorizado o desmatamento de 36,00 ha, que representou $2,24 \%$ do total de desflorestamento informado pela SEMA, consequentemente $97,76 \%$ de desmatamento ilegal. Em relação ao biênio 2013/2014, o IMAP emitiu autorizações de desmatamento totalizando aproximadamente $7 \%$ do desflorestamento informado pela SEMA.

Em 2009 e 2010, o município de Tartarugalzinho desmatou 97,78\%, sem autorização, do total 1618,00 ha, detectado pela SEMA (COSTA et al., 2017). Os assentamentos são os principais causadores de desflorestamento na Amazônia nos últimos anos (FEARNSIDE, 1999; FEARNSIDE, 2001). O desflorestamento tem sido destacado principalmente pela mudança no tamanho dos polígonos, passando de grande para pequenas áreas (ALENCAR et al., 2016; MMA, 2013). Para Alencar et al. (2016), as áreas de polígonos de floresta desmatadas no período de 2010 a 2014 no estado do Amapá, foram de pequenas áreas, realizadas em até 10 ha.

No estado do Amapá, a agricultura familiar nos projetos de assentamentos, contribui com grande parte na taxa de desmatamento, através de revezamento de terras (DOMINGUES et al., 2004; AMAPÁ, 2009). Este revezamento correlacionado com a variação da área produz constante desmate e queimada, 
Geotecnologia aplicada ao desflorestamento aponta 92\% de desflorestamento ilegal em projeto de assentamento cedro no município de

caracterizando o chamado desmatamento silencioso, que são difíceis de serem detectados por imagens de satélites (DOMINGUES et al., 2004).

De acordo pesquisa realizada por Batista (2009), para o período compreendido entre os anos 2001 a 2006, os desmatamentos ocorridos nos projetos de assentamentos, principalmente, os de jurisdição do Instituto Nacional de Colonização e Reforma Agrária (INCRA-AP), representou um percentual de 25,5\% (38.358 ha) do total de áreas desmatadas no estado do Amapá.

Assim como em outros estudos (AMAPÁ, 2016), a estimativa de desmatamento nos assentamentos vem crescendo. No biênio 2013-2014, o desmatamento foi de $21,27 \mathrm{Km}^{2}$, sendo que, a maior incidência de desmatamentos ocorreu nos assentamentos localizados na região central e ao norte do estado (AMAPÁ, 2016).

Atualmente, o desflorestamento na Amazônia Legal é monitorado através de imagens de satélites LANDSAT, CBERS e MODIS, pelo Programa de Monitoramento da Amazônia por Sensoriamento Remoto do INPE. Neste programa encontra-se o Projeto de Monitoramento de Desflorestamento na Amazônia Legal (PRODES) que realiza o monitoramento desde 1988, estimando taxas anuais de desmatamento na região amazônica (CÂMARA et al., 2006; INPE, 2008).

A partir do ano de 2002, foi implantada uma nova metodologia que anteriormente era de apenas na interpretação das imagens, passando a verificar também a classificação digital das imagens. O PRODES permitiu a divulgação das estimativas anuais com os polígonos de desflorestamento, representando o incremento da área que sofreu o desflorestamento (INPE, 2008).

No estado de Mato Grosso, em 2016, de todo o desmatamento identificado pelo INPE, $1.508 \mathrm{~km}^{2}$, $95 \%$ correspondeu ao desmatamento ilegal, que chegou a $1.440 \mathrm{~km}^{2}$, apenas $68,8 \mathrm{~km}^{2}(4,6 \%)$ foi realizado em áreas com autorização de desmatamento (ICV, 2017). Mato Grosso foi o segundo estado com maior área desmatada, ficando atrás apenas do estado do Pará, que converteu $3.025 \mathrm{~km}^{2}$ de florestas em área desmatada.

Apesar de ambos os órgãos empregarem os mesmos dados de sensoriamento remoto como insumo principal da análise do desmatamento, as metodologias utilizadas são diferentes, o que resulta na geração de dados e informações diferenciadas. A fundamental diferença metodológica está na Unidade Mínima de Mapeamento (LUZ, 2002; AMAPÁ, 2014; ANDERSON, 2015).

Enquanto que a SEMA identifica a área desmatada do tipo corte raso e também alterações da cobertura florestal em geral, em áreas superiores a 0,10 ha, o Projeto PRODES/INPE detecta unicamente o desmatamento onde é realizado o corte raso da floresta em áreas superiores a 6,25 ha. Tal escala tende a mascarar áreas desmatadas, especialmente, em lotes existentes nos projetos de assentamentos, onde levam, em média, de 2 a 3 anos consecutivos para desmatar tal quantitativo (BATISTA, 2009).

Um entrave, é que a estimativa da taxa de desmatamento utiliza apenas imagens ópticas e que a existência de nuvens dificulta a coleta e interpretação dos focos de desmatamentos. Isto por que, entre os estados da Amazônia Legal, o Amapá é o que apresenta a maior média de proporção de cobertura de nuvens 
Geotecnologia aplicada ao desflorestamento aponta 92\% de desflorestamento ilegal em projeto de assentamento cedro no município de

por ano (ASNER, 2001). Porém a busca pela imagem é feita para todo o acervo anual disponível, a fim de obter as imagens com menor quantidade de nuvens para cada cena, enquanto o PRODES usualmente utiliza imagens do mês de agosto. Por conta disto, as taxas bianuais da SEMA se referem às alterações observadas na melhor imagem do período estimado, isso implicou na escolha das taxas bianuais da SEMA para o estudo realizado (AMAPÁ, 2014).

O PA Cedro possuía 95,17 \% de área de floresta em sua criação, em 1996. Não podemos descartar a importância das legislações vigentes, com o objetivo de reservar áreas florestadas. Em 2002 foram definidos procedimentos de conversão de uso do solo através de autorização de desmatamento nos imóveis e propriedades rurais de até três hectares, em Projetos de Assentamento da Reforma Agrária na Amazônia Legal (BRASIL, 2002). A emissão de autorização deve ser concedida após vistoria feita pelo órgão competente, obedecendo aos limites máximos permitidos de desmatamento e de manutenção da Reserva Legal e das Áreas de Preservação Permanente (BRASIL, 2005).

A SEMA, com a preocupação do avanço do desflorestamento sobre a vegetação nativa, desenvolveu através da sua Divisão de Geoprocessamento - DGEO, desde 2003 o monitoramento sistemático da dinâmica de uso da cobertura vegetal do estado com o auxílio de imagens de satélite (AMAPÁ, 2005). Os Relatórios técnicos de desmatamento orientam a Secretaria nas ações de controle e educação ambiental uma vez que permite identificar as áreas que sofrem maiores pressões antrópicas sobre o uso e exploração dos recursos naturais no Estado (AMAPÁ, 2005).

A gestão florestal do Estado do Amapá até o início do ano de 2007 era de responsabilidade do Governo Federal, por intermédio do IBAMA. Com a criação da Lei Federal № 11.284, de 2 de março de 2006 passou a ser do Estado do Amapá, que inicialmente foi executada pela SEMA. A partir do segundo semestre de 2007, as autorizações de desmatamento começaram a ser emitidas pelo IMAP, com o auxílio do Sistema de Produtos Florestais - SISPROF do IBAMA. Permanecendo para o IBAMA somente a responsabilidade sobre o procedimento administrativo referente à supressão de vegetação nativa, localizado no domínio da União.

O Plano de Prevenção e Controle do Desmatamento e Queimadas no Estado do Amapá - PPCDAP teve como principal objetivo a redução de desmatamentos ilegais em áreas consideradas críticas e a garantia da manutenção de suas florestas nativas, com o auxílio de ações de monitoramento, licenciamento e fiscalização (AMAPÁ, 2009).

Atualmente as autorizações de desmate são emitidas de acordo com a Lei № 12.651, de 25 de maio de 2012, com a Instrução Normativa № 3, de 4 de março de 2002 - IBAMA e a Instrução Normativa № 75, de 25 de agosto de 2005-IBAMA. Estas legislações definem os procedimentos e documentação necessária par a obtenção de autorização de desmatamento.

Com o Novo Código Florestal, a Lei № 12.651, de 25 de maio de 2012, a delimitação da área de Reserva Legal está nos arts. 12 a 16 do capítulo IV que discorrem que todo imóvel rural deve manter área com cobertura de vegetação nativa, a título de Reserva Legal, observados na Amazônia Legal os 80\% (oitenta por cento), no imóvel situado em área de florestas, 35\% (trinta e cinco por cento), no imóvel situado em área 
Geotecnologia aplicada ao desflorestamento aponta 92\% de desflorestamento ilegal em projeto de assentamento cedro no município de tartarugalzinho no estado do Amapá

de cerrado e $20 \%$ (vinte por cento), no imóvel situado em área de campos gerais, excetuados os casos previstos no art. 68 desta Lei.

\section{CONCLUSÕES}

Conclui-se que a geotecnologia é uma ferramenta de destaque devido a sua funcionalidade, demonstrando a possibilidade e necessidade da aplicação de geoprocessamento para a análise do desmatamento legal, através da espacialização das autorizações de desmatamento, de maneira com que as informações sejam precisas. Nesse contexto, SIG como ferramenta de subsidio na tomada de decisão mostrase ser um importante instrumento que traz resultados relevantes.

Com a aplicação de técnicas de geoprocessamento foi possível espacializar as autorizações de desmatamento, resultando na identificação e análise do desmatamento não autorizado no PA Cedro, quantificando-o, no período estudado. Tal resultado mostra que $92,89 \%$, do total de 2237,32 hectares, ou seja, mais aproximadamente $93 \%$ do desflorestamento detectado pela Secretaria de Estado e Meio Ambiente foi realizado ilegalmente no estado do Amapá, no período de 2009 a 2014.

O presente estudo, destaca que a metodologia pode ser replicada e os resultados gerados de acordo com a análise do desmatamento ilegal no PA Cedro, que identificou e quantificou o desmatamento ilegal naquela região, devendo auxiliar as autoridades competentes em tomada de decisões que envolve o desmatamento ilegal e que aplicações de políticas públicas sejam utilizadas para minimizar e até mesmo erradicar o desmatamento ilegal naquela região e que possam ser objeto de novos estudos.

\section{REFERÊNCIAS}

ALENCAR, A.; PEREIRA, C.; CASTRO, I.; CARDOSO, A.; SOUZA, L.; COSTA, R.; BENTES, A. J.; STELLA, O.; AZEVEDO, A.; GOMES, J.; NOVAES, R.. Desmatamento nos Assentamentos da Amazônia: Histórico, Tendências e Oportunidades. Brasília: IPAM, 2016.

ANDERSON, A.. Diretrizes de um Programa de REDD+ para o Estado do Amapá. Macapá: Instituto Estadual de Florestas do Amapá, 2015.

AMAPÁ. Relatório Técnico de Desmatamento no Estado do Amapá, referente a 2004. Macapá: Secretaria de Estado do Meio Ambiente, 2005.

AMAPÁ. Programa de Prevenção e Controle do Desmatamento e Queimadas do Estado do Amapá PPCDAP. Macapá: Secretaria Especial de Desenvolvimento Econômico do Estado e Secretaria de Estado do Meio Ambiente, 2009.

AMAPÁ. Relatório Técnico de Desmatamento no Estado do Amapá, referente ao período 2011 a 2012. Macapá: Secretaria de Estado do Meio Ambiente, 2014.

AMAPÁ. Plano Anual de Outorga Florestal 2015. Macapá: Instituto Estadual de Florestas do Amapá - IEF/AP, 2014.
AMAPÁ. Relatório Técnico de Desmatamento no Estado do Amapá, referente ao período 2013 a 2014. Macapá: Secretaria de Estado do Meio Ambiente, 2016.

ASNER, G. P.. Cloud cover in Landsat observations of the Brazilian Amazon. International Journal of Remote Sensing, Bristol, v.22, n.18, p.3855-3862, 2001. DOI: http://dx.doi.org/10.1080/01431160010006926

BATISTA, E. M.. O desmatamento em Projetos de Colonização e Reforma Agrária situados no Estado do Amapá. In: SIMPÓSIO BRASILEIRO DE SENSORIAMENTO REMOTO, 14. Anais. Natal: Centro de Convenções, 2009.

BECKER, B. K.. Undoing Myths: The Amazon - An Urbanized forest. In: CLÜSENER, G. M.; SACHS, I.. Brazilian Perspectives on sustainable development of the Amazon region - Man and Biosphere Series. France: UNESCO e Parthenon Publish Group Limited, 1995. p.53-89.

BECKER, B. K.. Mesa Redonda: Sensoriamento Remoto e a questão urbana na Amazônia. In: SIMPÓSIO BRASILEIRO DE SENSORIAMENTO REMOTO, 10. Anais. Foz do Iguaçu, 2001.

BECKER, B. K.. Amazônia - Geopolítica na Virada do III Milênio. Garamond, 2005. 
BRASIL. Informativo técnico: Desmatamento. Brasília: Ministério do Meio Ambiente. IBAMA, 2003.

CÂMARA, G.; VALERIANO, D. M.; SOARES, J. V.. Metodologia para o Cálculo da Taxa Anual de Desmatamento na Amazônia Legal. São José dos Campos: INPE, 2006.

COSTA, J. D. M.; CARMONA, S. L. S.; FUNI, C.. Análise espacial do desflorestamento legal no estado do Amapá. In: SIMPÓSIO BRASILEIRO DE SENSORIAMENTO REMOTO, 18. Anais. Santos: Mendes Convention Center, 2017.

ICV. Análise do desmatamento em Mato Grosso (Prodes/2016). Cuiabá: Instituto Centro de Vida - ICV, 2017.

DOMINGUES, E.; PEREIRA, R. F.; GAMA, A. M. R. C.; RIBEIRO, G. V.; ALVES, P. S. P. F.; FERNANDES, N. P.; LEITE, P. F.; GOMES, S. O.; AQUINO, A. M. F. A.; LIMA, S. S. C.. Cobertura e Uso da Terra no Estado do Amapá. Rio de Janeiro: IBGE, 2004.

DRUMMOND, J. A.; DIAS, T. C. A. C.; BRITO, D. M. C.. Atlas das Unidades de Conservação do Estado do Amapá. Macapá: MMA/IBAMA-AP; GEA/SEMA, 2008.

FEARNSIDE, P. M.. Combate ao desmatamento na Amazônia brasileira. In: Instituto Ambiental do Paraná. Cadernos da Biodiversidade, Curitiba, v.2, n.2, p.12-29, 1999.

FEARNSIDE, P. M.. Land-Tenure Issues as Factors in Environmental Destruction in Brazilian Amazonia: the case of southern Pará. World Development, v.29, n.8, p.1361-1372, 2001. DOI: http://doi.org/10.1016/S0305-750X(01)00039-0

FEARNSIDE, P. M.. A floresta amazônica nas mudanças globais. Manaus: INPA, 2003.

FLORENZANO, T. G.. Geomorfologia: conceitos e tecnologias atuais. São Paulo: Oficina de Textos, 2008.

GRISI, B. M.. Glossário de ecologia e ciências ambientais. 2 ed. João Pessoa: UFPB, 2000.

GOLFARI, L.; CASER, R. L.; MOURA, V. P. G.. Zoneamento ecológico esquemático para reflorestamento no Brasil. Belo Horizonte: PRODEPEF, 1978.

\section{ICMBIO. PLANO DE MANEJO DA FLORESTA NACIONAL DO} AMAPÁ Volume I- Diagnóstico. ICMBio. Macapá: AP, 2014.

INCRA. Relatório Assentamentos - Informações Gerais. Superintendência Regional do Amapá (SR-21). Instituto
Nacional de Colonização e Reforma Agrária - INCRA.

Macapá: AP, 2016.

INPE. Monitoramento da cobertura florestal da Amazônia por satélites: sistemas PRODES, DETER, DEGRAD E QUEIMADAS 2007-2008. São José dos Campos: Instituto Nacional de Pesquisas Espaciais - INPE, 2008.

IBGE. Censo Demográfico 2010. Rio de Janeiro: Instituto Brasileiro de Geografia e Estatística, 2012.

HOMMA, A. K. O.; WALKER, R.T .; SEATENA, E. N.; CONTO, A. J.; CARVALHO, R. A.; SANTOS, A. L. M.. Redução dos Desmatamentos na Amazônia: política agrícola ou ambiental?. In: CONGRESSO BRASILEIRO DE ECONOMIA E SOCIOLOGIA RURAL, 33. Anais. Curitiba, 1995.

KITAMURA, P. C.. A Amazônia e o Desenvolvimento Sustentável. São Paulo: Embrapa, 1994.

LEMOS, A. L. F.; SILVA, J. A.. Desmatamento na Amazônia Legal: evolução, causa, monitoramento e possibilidades de mitigação através do fundo Amazônia. Floresta e Ambiente, Rio de Janeiro, v.18, n.1, p.98-108, 2011. DOI: http://doi.org/10.4322/floram.2011.027

LUZ, N.. Análise espacial como subsídio à recuperação de ecossistemas apoiada na ecologia de paisagens e imagens Ikonos. Dissertação (Mestrado em Engenharia Florestal) Universidade Federal do Paraná, Curitiba, 2002.

MARGULIS, S.. Causas do desmatamento na Amazônia brasileira. Brasília: The Word Bank, 2003.

MILARÉ, É.. Direito do Ambiente - A Gestão Ambiental em Foco (Doutrina, Jurisprudência e Glossário). 6 ed. São Paulo: Revista dos Tribunais, 2009.

MMA. Ministério do Meio Ambiente. Plano de Ação para Prevenção e Controle do desmatamento na Amazônia Legal - PPCDAM 1a fase. Brasília: Ministério do Meio Ambiente, 2004.

MMA. Ministério do Meio Ambiente. Plano de Ação para prevenção e controle do desmatamento na Amazônia Legal - PPCDAM 3a fase. Brasília: Ministério do Meio Ambiente, 2013.

WALKER, R.; MORAN, E.; ANSELIN, L.. Deforestation and cattle ranching in the Brazilian Amazon: external capital and household processes. World Development, v.28, n.4, p.683-699, 2000

A CBPC - Companhia Brasileira de Produção Científica (CNPJ: 11.221.422/0001-03) detém os direitos materiais desta publicação. Os direitos referem-se à publicação do trabalho em qualquer parte do mundo, incluindo os direitos às renovações, expansões e disseminações da contribuição, bem como outros direitos subsidiários. Todos os trabalhos publicados eletronicamente poderão posteriormente ser publicados em coletâneas impressas sob coordenação da Sustenere Publishing, da Companhia Brasileira de Produção Científica e seus parceiros autorizados. Os (as) autores (as) preservam os direitos autorais, mas não têm permissão para a publicação da contribuição em outro meio, impresso ou digital, em português ou em tradução. 